\title{
Endothelin but Not Angiotensin II May Mediate Hypertension-Induced Coronary Vascular Calcification in Chronic Kidney Disease
}

\author{
Simon W. Rabkin \\ University of British Columbia, Level 9, 2775 Laurel Street, Vancouver, BC, Canada V5Z 3J5 \\ Correspondence should be addressed to Simon W. Rabkin, rabkin@interchange.ubc.ca
}

Received 21 March 2011; Accepted 26 March 2011

Academic Editor: Domenico Russo

Copyright (c) 2011 Simon W. Rabkin. This is an open access article distributed under the Creative Commons Attribution License, which permits unrestricted use, distribution, and reproduction in any medium, provided the original work is properly cited.

\begin{abstract}
To understand the relationship between putative neurohormonal factors operative in hypertension and coronary artery calcification (CAC), the relevant cellular actions of angiotensin (Ang II) and endothelin-1 (ET-1) are reviewed. There is compelling evidence to implicate ET-1 in CAC. ET-1 increases phosphate transport with a 42 to $73 \%$ increase in $V_{\max }$. Increased cellular phosphate may induce CAC through increased Ca x phosphate product, transformation of vascular smooth muscle cells into a bone-producing phenotype or cell apoptosis that releases procalcific substances. ET-1 is increased in several models of vascular calcification. ET-1 inhibits inhibitors of calcification, matrix Gla and osteoprotegerin, while enhancing pro-calcific factors such as BMP-2 and osteopontin. In contrast, Ang II inhibits phosphate transport decreasing $V_{\max }$ by $38 \%$ and increases matrix Gla. Ang II also stimulates bone resorption. Vascular calcification is reduced by ET-1 A receptor antagonists and to a greater extent than angiotensin receptor blockade although both agents reduce blood pressure.
\end{abstract}

\section{Introduction}

The presence and severity of coronary artery calcification (CAC) is a predictor of an increased probability of serious clinical cardiac events including death [1-4]. Chronic kidney disease is associated with increased CAC, and in general the more advanced the stage of kidney disease, the greater is the amount of CAC [5-9]. The possible causal linkage between end-stage kidney diseases producing CAC that in turn accelerates coronary atherosclerotic events has focused attention on the pathophysiology of CAC in end stage renal disease with the objective of determining steps in the process that might be amenable to a suitable intervention to reduce the high mortality seen in patient with chronic kidney disease.

While the precise mechanisms producing vascular calcification are still being elucidated, investigators contend that the processes likely involve calcium and phosphorus metabolic dysfunction, changes of vascular cells, especially vascular smooth cells (VSMC), into an osteoblastic phenotype and an imbalance between procalcification and anti- calcification factors [10]. Vascular calcification in chronic kidney disease vessels is also strongly associated with vascular smooth muscle cell death resulting from calcium- and phosphate-induced apoptosis $[11,12]$. Vascular calcification induced in aortas cultured in a high phosphate medium occurs concomitantly with cell death of VSMC via apoptosis [13]. Inhibition of apoptosis with a general caspase inhibitor reduces calcification [13]. Calcification can be initiated by the release of membrane-bound matrix vesicles from living VSMC and also by the release of apoptotic bodies from dying cells [12]. Vesicles released by VSMC after prolonged exposure to calcium and phosphate not only accelerate vascular calcification but also contain preformed calcium phosphate complexes [12].

Hypertension is an important risk factor for CAC [14]. Indeed, some data suggest that the presence of hypertension is the most important determinant of CAC in patients with chronic kidney disease (CKD). The association between lower eGFR and higher prevalence of CAC in the Framingham study was attenuated and of less statistical significance after multivariable adjustment for risk factors including 
hypertension [5]. Amongst the 6749 participants of the Multiethnic Study of Atherosclerosis, hypertension was a major factor accounting for the association of decrements of kidney function and CAC after adjustment for age, gender, and race/ethnicity [15]. In a multivariate analysis of patients with CKD, after considering many factors, the severity of hypertension, reflected by the number of antihypertensive drugs taken to control hypertension, was significantly associated with CAC with an odds ratio of 2.4 compared to patient's age that had an odds ratio of 1.1 [16].

Hypertension is produced by a wide variety of factors operating in different organs. Two factors that have been implicated in the pathogenesis of hypertension are the angiotensin and Endothelin family of peptides. Angiotensin II is a powerful vasoconstrictor peptide. Endothelin, an even more potent vasoconstrictor peptide, is released from endothelial as well as other cell types. This paper examines the effect of angiotensin II (Ang II) and Endothelin 1 (ET-1) on vascular calcification focusing on differences in putative pathways leading to vascular calcification. Despite similar effects on blood pressure, these two peptides produce different effects on the process of calcification. These differences are reflected in different cellular actions especially on cellular phosphate transport.

\section{Phosphate Transport into Cells: Contrasting Effects of ET-1 and Ang II}

CAC in chronic kidney disease (CKD) has been strongly linked to the hyperphosphatemia in severe CKD [17-20]. Predictors of CAC are higher serum phosphorus levels, lower eGFR levels, and traditional CVD risk factors [21]. Each $1-\mathrm{mg} / \mathrm{dl}$ increase in serum phosphorus increases the odds ratios for CAC by 1.5 (prevalence) or 1.6 (incidence) [21]. The reduction in CAC found in some dialysis patients who received renal transplantation correlated with a decrease in calcium $\mathrm{x}$ phosphate product, in the early period after renal transplantation [22]. These data support the contention that increased phosphate transport into VSMC may initiate the process of vascular calcification.

Cellular phosphate transport exhibits saturable uptake (Figure 1). VSMC express both high affinity $\mathrm{Na}$-dependent and Na-independent components of Pi transport with similar kinetic behavior [23]. The Na-coupled saturable uptake has been explained by the expression of two type III sodiumdependent phosphate cotransporter proteins, Pit1 and Pit2 [23]. Phosphate uptake into the aorta through Pit-1 can lead to VSMC calcification by induction of apoptosis [13] or by phosphate-induced phenotypic changes in VSMC to a cell with the capacity to produce calcification [24]. The influx of phosphate through capillary membranes is mediated by a saturable high-affinity system which is independent of sodium [25], but presumably, it is cellular phosphate concentration rather than the transporter that regulates cellular calcification.

Ang II produces a concentration-dependent reduction in cellular phosphate transport (Figure 2) [26]. In some tissues such as isolated bovine capillaries, however, Ang II

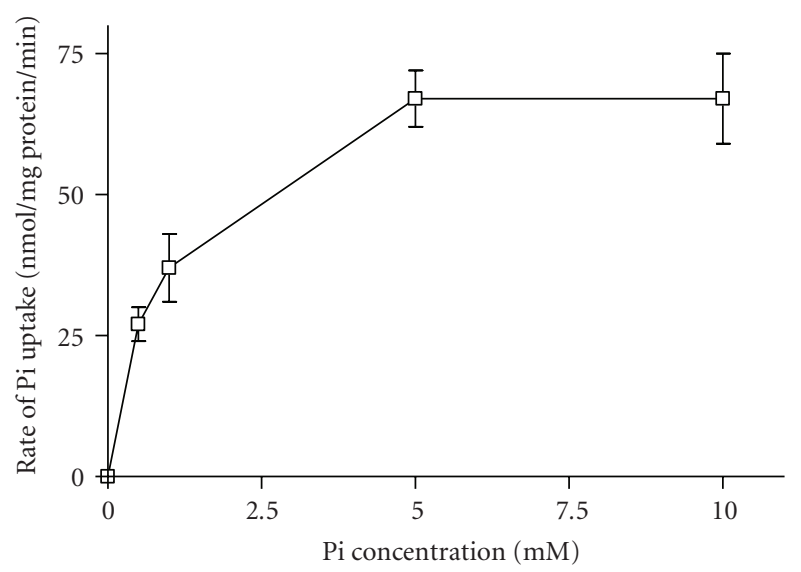

FIGURE 1: Uptake of phosphate in the presence of various concentrations of phosphate $(\mathrm{Pi})$. The data are the mean + SEM. The data are adapted from Sunga and Rabkin [26].

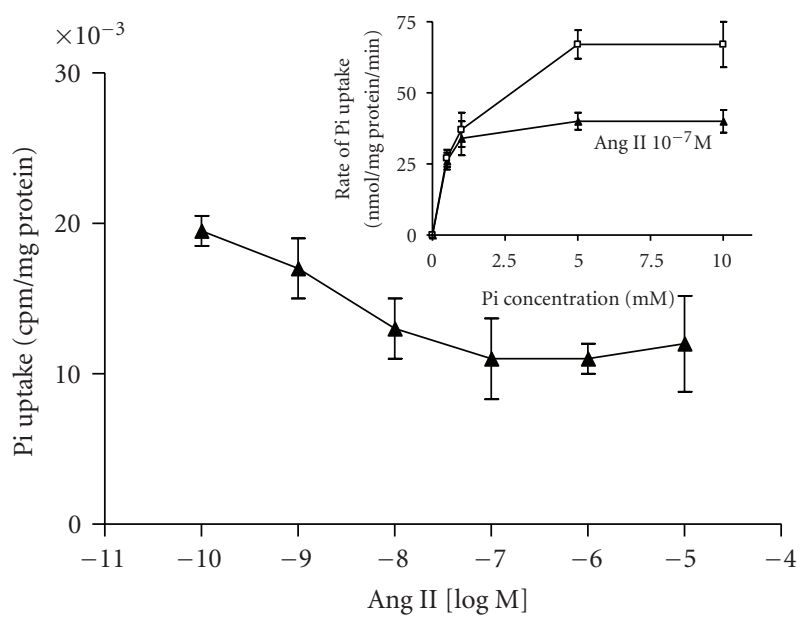

FIGURE 2: Inhibition of phosphate uptake in response to various concentrations of Ang II. The inset shows the effect of Ang II $\left(10^{-7} \mathrm{M}\right)$ on phosphate uptake in the presence of various extracellular phosphate concentrations. The data are adapted from Sunga and Rabkin [26].

does not affect phosphate transport [27] suggesting that the effect of Ang II impacts the type III sodium-dependent phosphate cotransporter. In contrast to Ang II, ET-1 has been consistently demonstrated to increase cellular phosphate transport. This has been demonstrated in capillaries [27], brush border membrane vesicles [28] and mouse calvariaderived osteoblast-like MC3T3-E1 cells [29]. In MC3T3E1 osteoblast-like cells, ET-1 stimulates sodium-dependent phosphate transport [29]. This effect is medicated through ET(A) and not ET(B) receptors [29]. ET1-induced stimulation of Pi transport is mediated by PKC activation through both phosphoinositide and phosphatidylcholine hydrolyses [29]. Considering the kinetics of phosphate transport, ET1 produces a 42 to $73 \%$ increase in $V_{\max }$, depending on tissue or cell type, in contrast to the $38 \%$ reduction in $V_{\max }$ observed in response to Ang II (Figure 3) [26, 28-30]. 


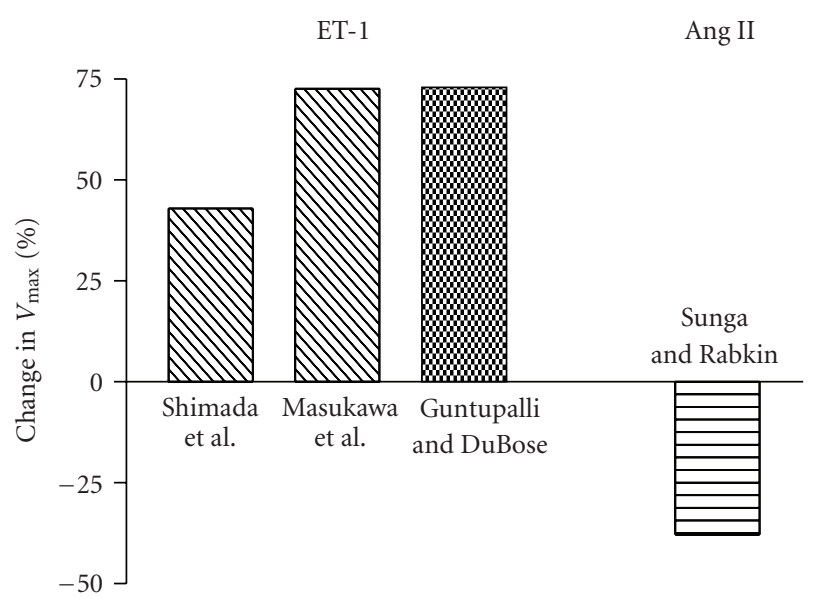

Figure 3: The effect of endothelin I (ET-1) and angiotensin II (Ang II) on the kinetics of phosphate uptake $V_{\max }$ in various studies.

\section{Effect of ET-1 on Vascular Calcification}

ET-1 may induce vascular calcification through its potential to induce VSMC apoptosis [31, 32]. VSMC apoptosis that occurs with increased arterial loading is further accentuated in the presence of ET-1 [31, 32]. Increases in arterial loading conditions increase endothelial prepro-ET-1 and VSMC endothelin $\mathrm{B}$ receptor expression [32] suggesting that the effects of ET-1 on the vasculature can be induced from blood pressure elevation regardless of its cause. The role of Ang II to mediate cell apoptosis is less clear [33,34].

Endothelin content and endothelin mRNA were increased in the model of vascular calcification in which VSMC are treated with beta-glycerophosphate [35]. In the in vivo model of vascular calcification induced by vitamin $\mathrm{D}$ (3) plus nicotine, endothelin levels in plasma and aorta as well as the amount of endothelin mRNA in calcified aorta are increased [35]. The ET-1 antagonist bosentan significantly reduced vascular calcification in this model [35]. ET 1-A receptor antagonists significantly regress the vascular calcification that is produced in the warfarin plus vitamin $\mathrm{K}$ model of vascular calcification [36]. The ability of an ET-1 A receptor antagonist to prevent vascular calcification was much greater than the angiotensin receptor blocker although both agents reduced blood pressure [37]. These data strongly implicate ET-1 in the pathogenesis of vascular calcification.

\section{Matrix Gla Protein (MGP), Fetuin, and Osteoprotegerin: Contrasting Effects of ET-1 and Ang II}

Matrix Gla protein (MGP) is a recognized inhibitor of vascular calcification. Ang II increased MGP mRNA levels by $20 \%$ in neonatal rat cardiac myocytes and $40 \%$ in cardiac fibroblasts [38]. Increases in this inhibitor of calcification would be expected to reduce vascular calcification. In contrast, ET-1 decreased MGP mRNA levels 30\% in myocytes and had no effect in fibroblasts [38]. Reductions in this inhibitor of vascular calcification would be expected to increase vascular calcification.

Osteoprotegerin (OPG) is an inhibitor of osteoclastogenesis and osteoclast activation. OPG inhibits advanced atherosclerotic plaque progression by preventing an increase in lesion size and lesion calcification [39]. In human aortic smooth muscle cells, Ang II produces a dose-dependent increase in the production of OPG [40]. A 3-fold increase in suprarenal aortic concentration of OPG was observed after chronic Ang II administration in ApoE(-/-) mice [40]. OPG secreted by explants of vascular tissue from human endarterectomy samples was significantly reduced within 48 hours of incubation with the Ang II receptor blocker irbesartan [41].

Fetuin-A inhibits pathologic calcification in both soft tissue and vasculature, even in the setting of atherosclerosis [42]. Fetuin uptake and secretion by proliferating and differentiating cells in the arterial wall is a protective mechanism against arterial calcification [43]. Circulating fetuin-A concentration decreases in parallel with decline in renal function [44]. During predialysis stage of diabetic nephropathy, there is a direct relationship between serum fetuin-A levels and CAC score [45]. The combination of fetuin-A deficiency, high-phosphate diet and CKD in ApoEdeficient mice greatly enhances calcification [42]. Thus factors that increase phosphate transport into the cell would be expected to enhance vascular calcification in the presence of low fetuin-A levels. ET-1 levels increase with declining renal function. Multiple regression analysis showed that fetuin-A was significantly inversely associated with ET-1 and the relationship was independent of estimated glomerular filtration rate, sex, parathyroid hormone, and the calcium $\mathrm{x}$ phosphorus product [44]. The negative correlation of coronary artery calcification scores with serum fetuin-A levels [46] coupled with the inverse relationship between fetuin-A and ET-1 suggests that fetuin and ET-1 have opposite actions leading to CAC. This possibility requires further investigation.

\section{Cellular Promoters of Calcification BMP-2 and Osteopontin: Effects of ET-1 and Ang II}

Although the role of bone morphogenic protein (BMP-2) in vascular calcification is still being elucidated, there are data that BMP-2 induces osteoblastic differentiation of VSMC through induction of MSX-2 or by inducing apoptosis of VSMC [47]. BMP-2 effects may be related to the loss of regulation of the matrix Gla protein [47]. In addition, BMP2 induces Runx2 and inhibits SM22 expression, indicating that it promotes osteogenic phenotype transition in these cells [48]. The action of BMP-2 can be related back to an effect on phosphate transport. BMP-2 upregulates Pit$1 \mathrm{mRNA}$ and protein levels [48]. Inhibition of phosphate uptake abrogated BMP-2-induced calcification suggesting that phosphate transport via Pit-1 is crucial in BMP-2 regulation of VSMC [48]. In the mouse osteoblast-like cell line MC3T3-E1, ET-1 significantly increased intracellular $\mathrm{Ca}^{2+}$ concentration, DNA synthesis, and cell number [49]. 


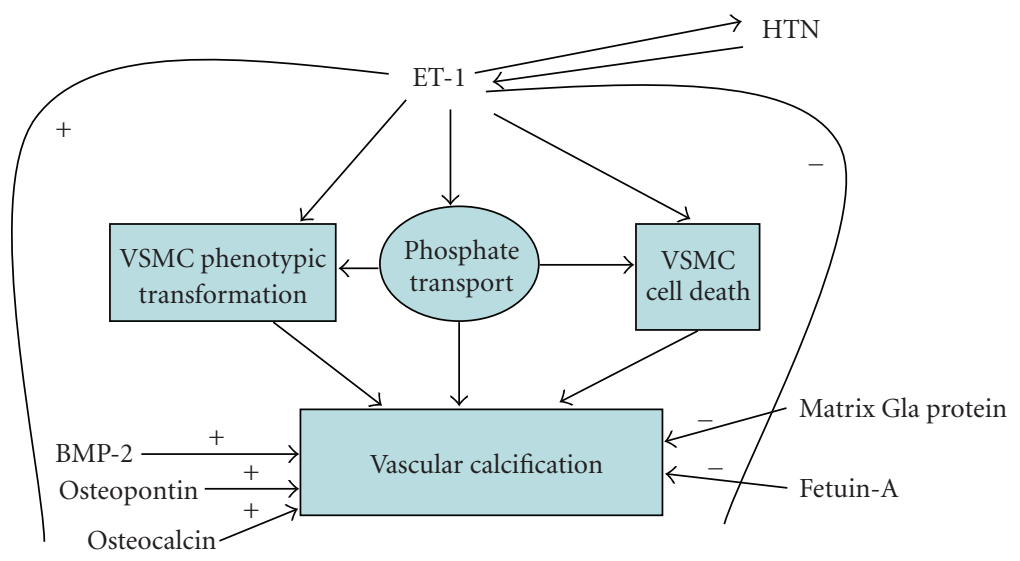

FIGURE 4: A simplified schematic of some of the putative effects of endothelin-1 (ET-1) leading to vascular calcification discussed in this paper.

The ability of ET-1 to induce mitosis and mitogen-activated protein kinase phosphorylation in VSMC were significantly increased in the presence of BMP-2 [50]. In vivo studies showed that tissue calcium content was significantly higher in the group that received both BMP-2 and ET-1 than in the group receiving BMP-2 alone [49]. The effect of ET-1 on bone formation is operative through $\mathrm{ET}(\mathrm{A})$ receptors [49].

Osteopontin (OPN), a low-affinity, high-capacity calcium-binding phosphoproteins, colocalizes with dystrophic arterial calcification. In human coronary artery segments, obtained at autopsy, there were high amounts of OPN in the outer margins of all diseased segments at each calcification front [51]. ET-1 consistently induces OPN in a number of different cell types [52-55]. ET-1 enhances OPN as well as various other factors that induce bone formation such as osteocalcin and bone sialoprotein [52]. ET-1 enhanced by approximately twofold the mRNA expression of both osteopontin and osteocalcin genes in rat osteoblastic osteosarcoma ROS17/2.8 cells [55]. ET-1 modulation of the expression of these two gene products of osteoblasts suggests that ET-1 plays a role in the regulation of bone metabolism [55].

Ang II produces similar effects on OPN as ET-1. Ang II also induces OPN expression in VSMC $[56,57]$. The effect of AngII on OPN is mediated by signaling cascades involving $\mathrm{G}(\mathrm{q} / 11)$, the Ras-ERK axis, p42/44 MAPK, and the Src kinase family and by the transcription factor, Ets-1 $[57,58]$.

\section{Effect of ET-1 and Ang II on Bone Formation}

The process of vascular calcification is analogous to bone formation. The putative effects of Ang II and ET-1 on vascular calcification are consistent with their effects on bone formation. ET-1 promotes both osteoblastic proliferation and differentiation leading to the formation of bone nodules in osteoblastic progenitor cells [59]. ET-1 modulation of the expression of the two phenotype-related gene products of osteoblasts suggests that ET-1 modulates osteoblastic functions and plays a role in the regulation of bone metabolism [55]. There is some contrary data. ET may decrease the expression of mRNA for osteocalcin, which is a marker protein for the maturation of osteoblastic cells and inhibit the mineralization of osteoblastic cells in vitro under some circumstances [60].

The effect of Ang II is different from ET-1. Ang II decreased alkaline phosphatase activity in bone cell populations derived from the periosteum of fetal rat calvariae consistent with reduction in bone formation [61]. Ang II also stimulates bone resorption. This has been demonstrated in both in vitro and in vivo models. Ang II stimulated bone resorption in cocultures of osteoclasts with osteoblastic cells [62]. In bone marrow-derived mononuclear cells, Ang II significantly increased osteoclasts via RANKL induction [63]. In a rat ovariectomy model of estrogen deficiency, administration of Ang II accelerated the decrease in bone density and Ang II receptor antagonism attenuated the decrease in bone density [63]. These data strongly point to a role for Ang II as factor that reduces the amount of bone mineralization.

\section{Conclusion}

In summary, the link between hypertension and coronary artery calcification can be related to an action of the vasoconstrictor peptide ET-1 on several processes that have been implicated in the pathogenesis of coronary artery calcification. This is illustrated in Figure 4. The ability of ET1 to consistently increase phosphate transport into the cell suggests that in conditions of hyperphosphatemia, that may occurs in end-stage chronic kidney disease, there is a heightened entry of phosphate into vascular smooth muscle. An increase in cellular phosphate can increase cellular calcification through at least three different mechanismsan increase in calcium $\mathrm{x}$ phosphate product transformation of VSMC to a bone-producing cell phenotype or cell apoptosis that releases procalcific substances. ET-1 affects other modulators of calcification in a manner that tips the balance in favor of calcification, namely, inhibiting the inhibitors of calcification, matrix Gla as well as osteoprotegerin and perhaps fetuin while enhancing the effects of procalcific factors such as BMP-2 and osteopontin. In contrast, another vasoconstrictor peptide operative in hypertension, angiotensin II, is highly unlikely to be responsible for coronary artery 
calcification. Ang II inhibits cellular phosphate transport, and increases the presence of inhibitors of calcification, matrix Gla protein and osteoprotegerin.

\section{References}

[1] R. D. Abbott, H. Ueshima, K. H. Masaki et al., "Coronary artery calcification and total mortality in elderly men," Journal of the American Geriatrics Society, vol. 55, no. 12, pp. 19481954, 2007.

[2] R. Erbel, S. Mhlenkamp, S. Moebus et al., "Coronary risk stratification, discrimination, and reclassification improvement based on quantification of Subclinical coronary atherosclerosis: the Heinz Nixdorf Recall study," Journal of the American College of Cardiology, vol. 56, no. 17, pp. 1397-1406, 2010.

[3] A. J. Taylor, J. Bindeman, I. Feuerstein, F. Cao, M. Brazaitis, and P. G. O'Malley, "Coronary calcium independently predicts incident premature coronary heart disease over measured cardiovascular risk factors: mean three-year outcomes in the Prospective Army Coronary Calcium (PACC) project," Journal of the American College of Cardiology, vol. 46, no. 5, pp. 807814, 2005.

[4] Y. W. Chiu, S. G. Adler, M. J. Budoff, J. Takasu, J. Ashai, and R. Mehrotra, "Coronary artery calcification and mortality in diabetic patients with proteinuria," Kidney international, vol. 77, no. 12, pp. 1107-1114, 2010.

[5] C. S. Fox, M. G. Larson, M. J. Keyes et al., "Kidney function is inversely associated with coronary artery calcification in men and women free of cardiovascular disease: the Framingham Heart Study," Kidney International, vol. 66, no. 5, pp. 20172021, 2004.

[6] H. Kramer, R. Toto, R. Peshock, R. Cooper, and R. Victor, "Association between chronic kidney disease and coronary artery calcification: the Dallas heart study," Journal of the American Society of Nephrology, vol. 16, no. 2, pp. 507-513, 2005.

[7] M. Bursztyn, M. Motro, E. Grossman, and J. Shemesh, "Accelerated coronary artery calcification in mildly reduced renal function of high-risk hypertensives: a 3-year prospective observation," Journal of Hypertension, vol. 21, no. 10, pp. 1953-1959, 2003.

[8] R. Mehrotra, M. Budoff, P. Christenson et al., "Determinants of coronary artery calcification in diabetics with and without nephropathy," Kidney International, vol. 66, no. 5, pp. 2022-2031, 2004.

[9] B. R. Kestenbaum, K. L. Adeney, I. H. D. Boer, J. H. Ix, M. G. Shlipak, and D. S. Siscovick, "Incidence and progression of coronary calcification in chronic kidney disease: the multiethnic study of atherosclerosis," Kidney International, vol. 76, no. 9, pp. 991-998, 2009.

[10] R. C. Johnson, J. A. Leopold, and J. Loscalzo, "Vascular calcification: pathobiological mechanisms and clinical implications," Circulation Research, vol. 99, no. 10, pp. 10441059, 2006.

[11] R. C. Shroff, R. McNair, N. Figg et al., "Dialysis accelerates medial vascular calcification in part by triggering smooth muscle cell apoptosis," Circulation, vol. 118, no. 17, pp. 1748-1757, 2008.

[12] J. L. Reynolds, A. J. Joannides, J. N. Skepper et al., "Human vascular smooth muscle cells undergo vesicle-mediated calcification in response to changes in extracellular calcium and phosphate concentrations: a potential mechanism for accelerated vascular calcification in ESRD," Journal of the American Society of Nephrology, vol. 15, no. 11, pp. 2857-2867, 2004.

[13] S. Mune, M. Shibata, I. Hatamura et al., "Mechanism of phosphate-induced calcification in rat aortic tissue culture: possible involvement of Pit-1 and apoptosis," Clinical and Experimental Nephrology, vol. 13, no. 6, pp. 571-577, 2009.

[14] L. F. Bielak, S. T. Turner, S. S. Franklin, P. F. Sheedy, and P. A. Peyser, "Age-dependent associations between blood pressure and coronary artery calcification in asymptomatic adults," Journal of Hypertension, vol. 22, no. 4, pp. 719-725, 2004.

[15] J. H. Ix, R. Katz, B. Kestenbaum et al., "Association of mild to moderate kidney dysfunction and coronary calcification," Journal of the American Society of Nephrology, vol. 19, no. 3, pp. 579-585, 2008.

[16] A. L. Ammirati, M. A. Dalboni, M. Cendoroglo, S. A. Draibe, and M. E. F. Canziani, "Coronary artery calcification, systemic inflammation markers and mineral metabolism in a peritoneal dialysis population," Nephron, vol. 104, no. 1, pp. c33-c40, 2006.

[17] S. M. Moe, "Vascular calcification and renal osteodystrophy relationship in chronic kidney disease," European Journal of Clinical Investigation, vol. 36, no. 2, supplement, pp. 51-62, 2006.

[18] G. A. Block, "Control of serum phosphorus: implications for coronary artery calcification and calcific uremic arteriolopathy (calciphylaxis)," Current Opinion in Nephrology and Hypertension, vol. 10, no. 6, pp. 741-747, 2001.

[19] S. M. Moe and N. X. Chen, "Pathophysiology of vascular calcification in chronic kidney disease," Circulation Research, vol. 95, no. 6, pp. 560-567, 2004.

[20] S. Jono, A. Shioi, Y. Ikari, and Y. Nishizawa, "Vascular calcification in chronic kidney disease," Journal of Bone and Mineral Metabolism, vol. 24, no. 2, pp. 176-181, 2006.

[21] K. R. Tuttle and R. A. Short, "Longitudinal relationships among coronary artery calcification, serum phosphorus, and kidney function," Clinical Journal of the American Society of Nephrology, vol. 4, no. 12, pp. 1968-1973, 2009.

[22] S. A. Abedi, M. K. Tarzamni, M. R. J. Nakhjavani, and A. Bohlooli, "Effect of renal transplantation on coronary artery calcification in hemodialysis patients," Transplantation Proceedings, vol. 41, no. 7, pp. 2829-2831, 2009.

[23] R. Villa-Bellosta, Y. E. Bogaert, M. Levi, and V. Sorribas, "Characterization of phosphate transport in rat vascular smooth muscle cells: implications for vascular calcification," Arteriosclerosis, Thrombosis, and Vascular Biology, vol. 27, no. 5, pp. 1030-1036, 2007.

[24] X. Li, H. Y. Yang, and C. M. Giachelli, "Role of the sodiumdependent phosphate cotransporter, Pit-1, in vascular smooth muscle cell calcification," Circulation Research, vol. 98, no. 7, pp. 905-912, 2006.

[25] L. Dallaire and R. Beliveau, "Phosphate transport by capillaries of the blood-brain barrier," The Journal of Biological Chemistry, vol. 267, no. 31, pp. 22323-22327, 1992.

[26] P. S. Sunga and S. W. Rabkin, "Regulation by angiotensin II of phosphate transport in cardiac myocytes," Biochemical Pharmacology, vol. 42, no. 5, pp. 1123-1128, 1991.

[27] L. Dallaire, S. Giroux, and R. Beliveau, "Regulation of phosphate transport by second messengers in capillaries of the blood-brain barrier," Biochimica et Biophysica Acta, vol. 1110, no. 1, pp. 59-64, 1992. 
[28] Y. Tomino, "Effects of endothelin 1 on phosphate transport in brush border membrane vesicles," Nephron, vol. 76, no. 1, pp. 72-76, 1997.

[29] H. Masukawa, Y. Miura, I. Sato, Y. Oiso, and A. Suzuki, "Stimulatory effect of Endothelin-1 on Na-dependent phosphate transport and its signaling mechanism in osteoblast-like cells," Journal of Cellular Biochemistry, vol. 83, no. 1, pp. 47-55, 2001.

[30] J. Guntupalli and T. D. DuBose Jr., "Effects of endothelin on rat renal proximal tubule $\mathrm{Na}+-\mathrm{P}(\mathrm{i})$ cotransport and $\mathrm{Na}+/ \mathrm{H}+$ exchange," American Journal of Physiology, vol. 266, no. 4, pp. F658-F666, 1994.

[31] M. Cattaruzza, C. Dimigen, H. Ehrenreich, and M. Hecker, "Stretch-induced endothelin B receptor-mediated apoptosis in vascular smooth muscle cells," FASEB Journal, vol. 14, no. 7, pp. 991-998, 2000.

[32] M. Cattaruzza, M. M. Berger, M. Ochs et al., "Deformationinduced endothelin B receptor-mediated smooth muscle cell apoptosis is matrix-dependent," Cell Death and Differentiation, vol. 9, no. 2, pp. 219-226, 2002.

[33] J. L. Bascands, J. P. Girolami, M. Troly et al., "Angiotensin II induces phenotype-dependent apoptosis in vascular smooth muscle cells," Hypertension, vol. 38, no. 6, pp. 1294-1299, 2001.

[34] J. Y. Kong and S. W. Rabkin, "Angiotensin II does not induce apoptosis but rather prevents apoptosis in cardiomyocytes," Peptides, vol. 21, no. 8, pp. 1237-1247, 2000.

[35] S. Y. Wu, B. H. Zhang, C. S. Pan et al., "Endothelin-1 is a potent regulator in vivo in vascular calcification and in vitro in calcification of vascular smooth muscle cells," Peptides, vol. 24, no. 8, pp. 1149-1156, 2003.

[36] R. Essalihi, V. Ouellette, H. H. Dao, M. D. McKee, and P. Moreau, "Phenotypic modulation of vascular smooth muscle cells during medial arterial calcification: a role for endothelin?" Journal of Cardiovascular Pharmacology, vol. 44, no. 1, pp. S147-S150, 2004.

[37] H. H. Dao, R. Essalihi, J. F. Graillon, R. Larivière, J. De Champlain, and P. Moreau, "Pharmacological prevention and regression of arterial remodeling in a rat model of isolated systolic hypertension," Journal of Hypertension, vol. 20, no. 8, pp. 1597-1606, 2002.

[38] E. Mustonen, V. Pohjolainen, J. Aro et al., "Upregulation of cardiac matrix Gla protein expression in response to hypertrophic stimuli," Blood Pressure, vol. 18, no. 5, pp. 286-293, 2009.

[39] B. J. Bennett, M. Scatena, E. A. Kirk et al., "Osteoprotegerin inactivation accelerates advanced atherosclerotic lesion progression and calcification in older $\mathrm{ApoE}^{-/-}$mice," Arteriosclerosis, Thrombosis, and Vascular Biology, vol. 26, no. 9, pp. 2117-2124, 2006.

[40] C. S. Moran, B. Cullen, J. H. Campbell, and J. Golledge, "Interaction between angiotensin II, osteoprotegerin, and peroxisome proliferator-activated receptor- $\gamma$ in abdominal aortic aneurysm," Journal of Vascular Research, vol. 46, no. 3, pp. 209-217, 2009.

[41] J. Golledge, M. McCann, S. Mangan, A. Lam, and M. Karan, "Osteoprotegerin and osteopontin are expressed at high concentrations within symptomatic carotid atherosclerosis," Stroke, vol. 35, no. 7, pp. 1636-1641, 2004.

[42] R. Westenfeld, C. Schäfer, T. Krüger et al., "Fetuin-A protects against atherosclerotic calcification in CKD," Journal of the American Society of Nephrology, vol. 20, no. 6, pp. 1264-1274, 2009.
[43] N. Wajih, T. Borras, W. Xue, S. M. Hutson, and R. Wallin, "Processing and transport of matrix $\gamma$-carboxyglutamic acid protein and bone morphogenetic protein-2 in cultured human vascular smooth muscle cells: evidence for an uptake mechanism for serum fetuin," The Journal of Biological Chemistry, vol. 279, no. 41, pp. 43052-43060, 2004.

[44] S. Cottone, A. Palermo, R. Arsena et al., "Relationship of fetuin-A with glomerular filtration rate and endothelial dysfunction in moderate-severe chronic kidney disease," Journal of Nephrology, vol. 23, no. 1, pp. 62-69, 2010.

[45] R. Mehrotra, R. Westenfeld, P. Christenson et al., "Serum fetuin-A in nondialyzed patients with diabetic nephropathy: relationship with coronary artery calcification," Kidney International, vol. 67, no. 3, pp. 1070-1077, 2005.

[46] S. M. Moe, M. Reslerova, M. Ketteler et al., "Role of calcification inhibitors in the pathogenesis of vascular calcification in chronic kidney disease (CKD)," Kidney International, vol. 67, no. 6, pp. 2295-2304, 2005.

[47] K. A. Hruska, S. Mathew, and G. Saab, "Bone morphogenetic proteins in vascular calcification," Circulation Research, vol. 97, no. 2, pp. 105-114, 2005.

[48] X. Li, H. Y. Yang, and C. M. Giachelli, "BMP-2 promotes phosphate uptake, phenotypic modulation, and calcification of human vascular smooth muscle cells," Atherosclerosis, vol. 199, no. 2, pp. 271-277, 2008.

[49] A. Someya, H. Yuyama, A. Fujimori, M. Ukai, S. Fukushima, and M. Sasamata, "Effect of YM598, a selective endothelin ET receptor antagonist, on endothelin-1-induced bone formation," European Journal of Pharmacology, vol. 543, no. 1-3, pp. 14-20, 2006.

[50] R. Yamanaka, F. Otsuka, K. Nakamura et al., "Involvement of the bone morphogenetic protein system in endothelin-and aldosterone-induced cell proliferation of pulmonary arterial smooth muscle cells isolated from human patients with pulmonary arterial hypertension," Hypertension Research, vol. 33, no. 5, pp. 435-445, 2010.

[51] L. A. Fitzpatrick, A. Severson, W. D. Edwards, and R. T. Ingram, "Diffuse calcification in human coronary arteries. Association of osteopontin with atherosclerosis," Journal of Clinical Investigation, vol. 94, no. 4, pp. 1597-1604, 1994.

[52] Z. Li, Z. Wang, L. Yang et al., "Fibroblast growth factor 2 regulates bone sialoprotein gene transcription in human breast cancer cells," Journal of Oral Science, vol. 52, no. 1, pp. 125-132, 2010.

[53] H. Chang-zheng, T. Jin, T. Juan et al., "Endothelin signaling axis activates osteopontin expression through PI3 kinase pathway in A375 melanoma cells," Journal of Dermatological Science, vol. 52, no. 2, pp. 130-132, 2008.

[54] K. Graf, Y. S. Do, N. Ashizawa et al., "Myocardial osteopontin expression is associated with left ventricular hypertrophy," Circulation, vol. 96, no. 9, pp. 3063-3071, 1997.

[55] M. Shioide and M. Noda, "Endothelin modulates osteopontin and osteocalcin messenger ribonucleic acid expression in rat osteoblastic osteosarcoma cells," Journal of Cellular Biochemistry, vol. 53, no. 2, pp. 176-180, 1993.

[56] D. deBlois, D. M. Lombardi, E. J. Su, A. W. Clowes, S. M. Schwartz, and C. M. Giachelli, "Angiotensin II induction of osteopontin expression and DNA replication in rat arteries," Hypertension, vol. 28, no. 6, pp. 1055-1063, 1996.

[57] K. Abe, H. Nakashima, M. Ishida et al., "Angiotensen IIinduced osteopontin expression in vascular smooth muscle cells involves Gq/11, Ras, ERK, Src and Ets-1," Hypertension Research, vol. 31, no. 5, pp. 987-998, 2008. 
[58] Z. Xie, D. R. Pimentai, S. Lohan et al., "Regulation of angiotensin II-stimulated osteopontin expression in cardiac microvascular endothelial cells: role of p42/44 mitogenactivated protein kinase and reactive oxygen species," Journal of Cellular Physiology, vol. 188, no. 1, pp. 132-138, 2001.

[59] H. P. von Schroeder, C. J. Veillette, J. Payandeh, A. Qureshi, and J. N. M. Heersche, "Endothelin-1 promotes osteoprogenitor proliferation and differentiation in fetal rat calvarial cell cultures," Bone, vol. 33, no. 4, pp. 673-684, 2003.

[60] Y. Hiruma, A. Inoue, A. Shiohama et al., "Endothelins inhibit the mineralization of osteoblastic MC3T3-E1 cells through the A-type endothelin receptor," American Journal of Physiology, vol. 275, no. 4, pp. R1099-R1105, 1998.

[61] S. Lamparter, L. Kling, M. Schrader, R. Ziegler, and J. Pfeilschifter, "Effects of angiotensin II on bone cells in vitro," Journal of Cellular Physiology, vol. 175, no. 1, pp. 89-98, 1998.

[62] R. Hatton, M. Stimpel, and T. J. Chambers, "Angiotensin II is generated from angiotensin I by bone cells and stimulates osteoclastic bone resorption in vitro," Journal of Endocrinology, vol. 152, no. 1, pp. 5-10, 1997.

[63] H. Shimizu, H. Nakagami, M. K. Osako et al., "Angiotensin II accelerates osteoporosis by activating osteoclasts," FASEB Journal, vol. 22, no. 7, pp. 2465-2475, 2008. 


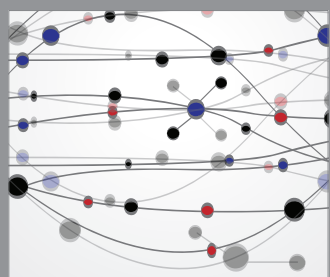

The Scientific World Journal
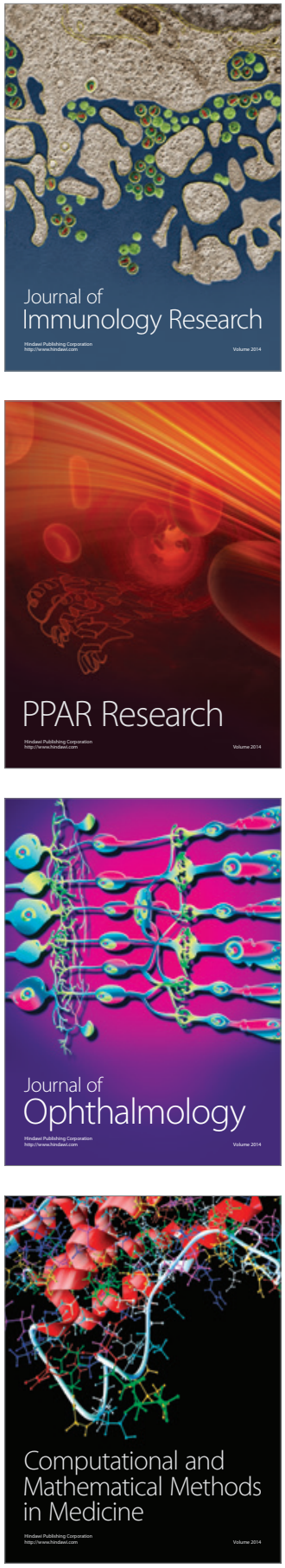

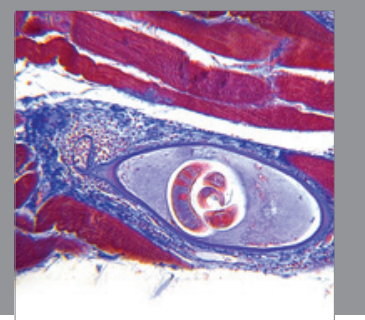

Gastroenterology

Research and Practice
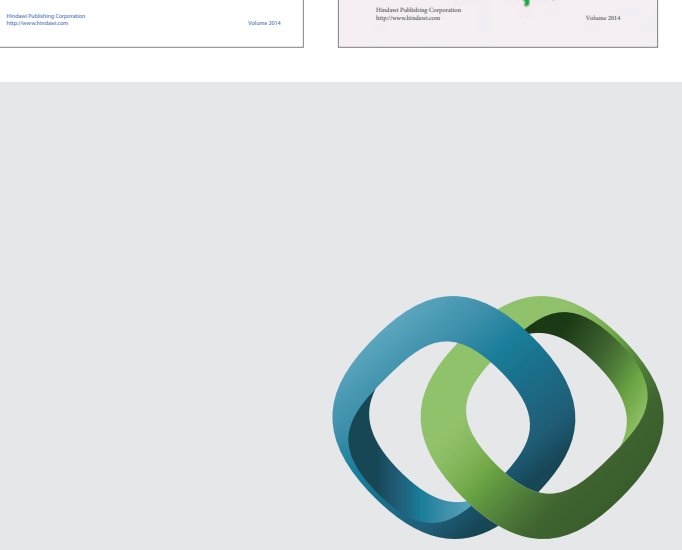

\section{Hindawi}

Submit your manuscripts at

http://www.hindawi.com
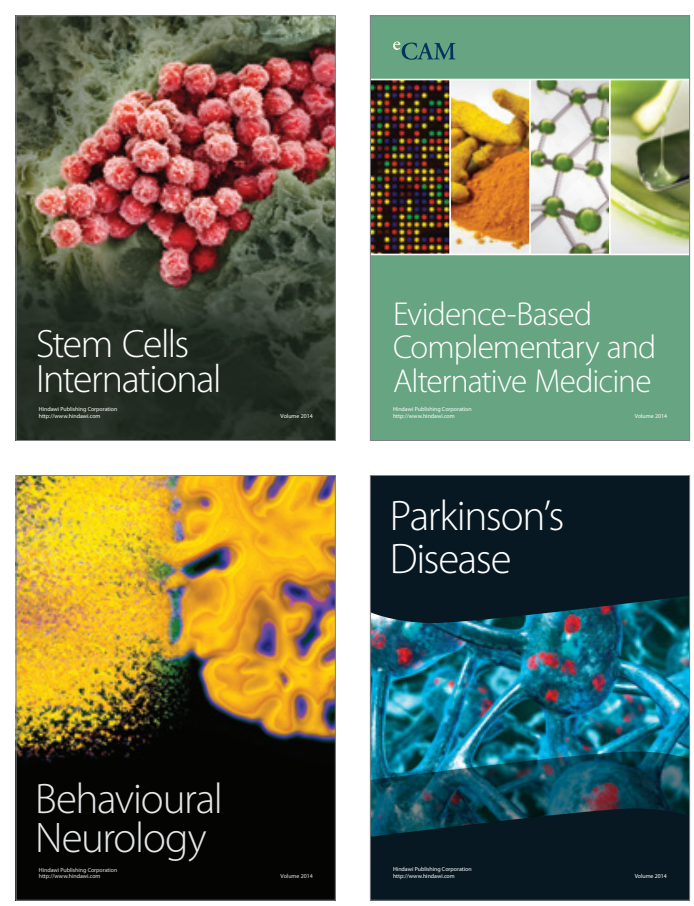

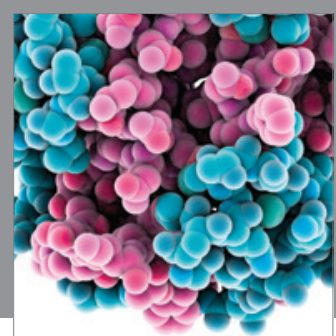

Journal of
Diabetes Research

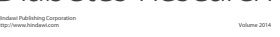

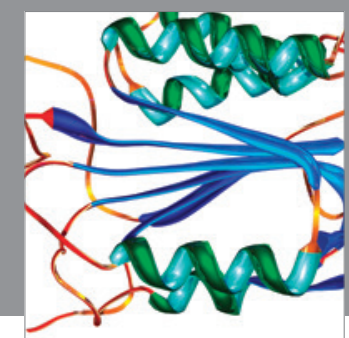

Disease Markers
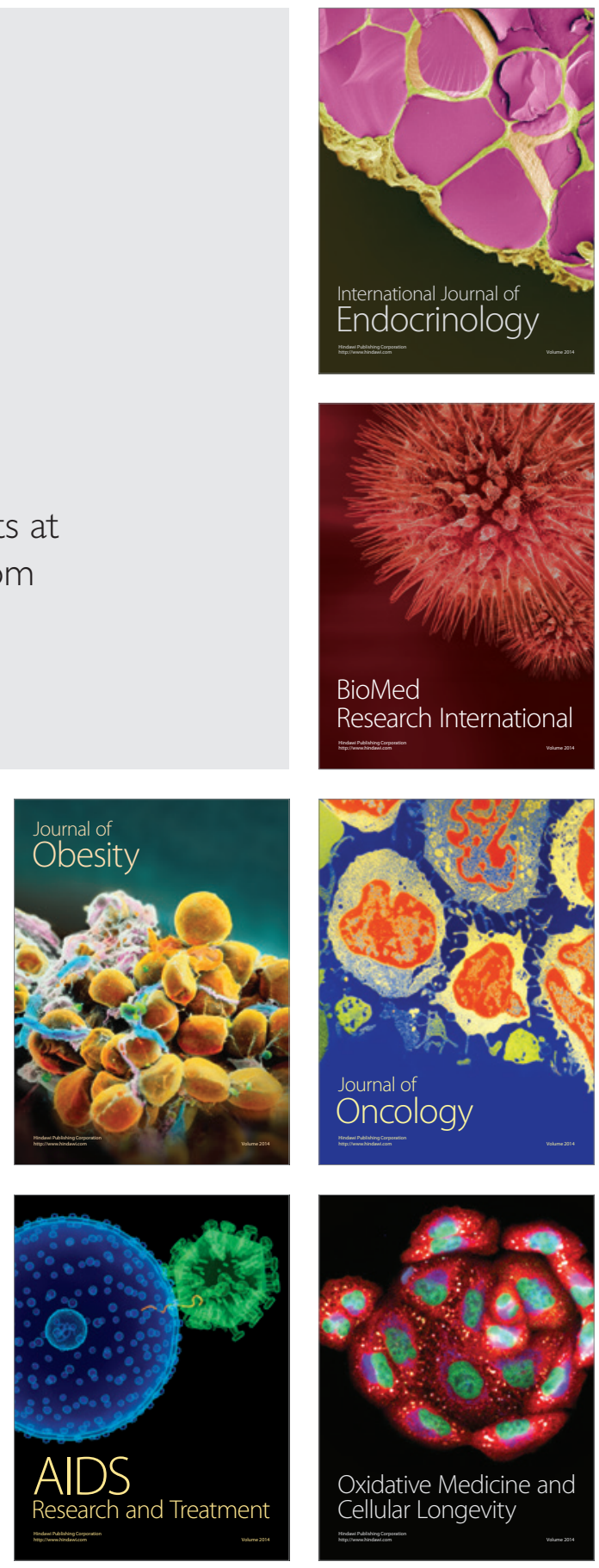